\title{
Hypopituitarism secondary to carotid artery aneurysm complicating a new presentation of hepatocellular carcinoma
}

\author{
Lavanta Farouk, Janine Makaronidis, Chidambaram Nethaji, Anukul Garg \\ Diabetes and Endocrinology \\ North Middlesex University Hospital NHS Trust, London, United Kingdom
}

\section{INTRODUGTION}

An 82 year old gentleman was admitted with lethargy, shortness of breath and $26 \%$ total body weight loss over 2 years. Past medical history included hypertension, pulmonary fibrosis, thalassaemia trait and unexplained thrombocytopenia. Previous investigation for weight loss in 2014 with a CT thorax/abdomen/pelvis and FDG PET demonstrated no evidence of malignancy.

\section{INVESTICATIONS}

\begin{tabular}{ccc} 
Hb & $69 \mathrm{~g} / \mathrm{L}$ & $(135-165)$ \\
Platelets & 115 & $(135-420)$ \\
Bilirubin & $83 \mathrm{\mu} / \mathrm{L}$ & $(<15)$ \\
ALT & $31 \mathrm{U} / \mathrm{L}$ & $(10-37)$ \\
AST & $130 \mathrm{U} / \mathrm{L}$ & $(10-37)$ \\
ALP & $165 \mathrm{U} / \mathrm{L}$ & $(40-129)$ \\
GGT & $167 \mathrm{U} / \mathrm{L}$ & $(0-55)$ \\
Albumin & $34 \mathrm{~g} / \mathrm{L}$ & $(35-50)$ \\
Cortisol & $276 \mathrm{nmol} / \mathrm{L}$ & \\
ACTH & $25 \mathrm{ng} / \mathrm{L}$ & $(<50)$ \\
TSH & $0.86 \mathrm{mU} / \mathrm{L}$ & $(0.35-5.5)$ \\
FT4 & $7.6 \mathrm{pmol} / \mathrm{L}$ & $(10-22.7)$ \\
Prolactin & $8127 \mathrm{mU} / \mathrm{L}$ & $(53-360)$ \\
Testosterone & $<0.3 \mathrm{nmol} / \mathrm{L}$ & $(4.4-27)$ \\
LH & $0.2 \mathrm{U} / \mathrm{L}$ & $(0.8-7.6)$ \\
FSH & $1.5 \mathrm{U} / \mathrm{L}$ & $(0.7-11.1)$ \\
IGF-1 & $2.7 \mathrm{nmol} / \mathrm{L}$ & $(6-36)$ \\
Ferritin & $673 \mathrm{ng} / \mathrm{ml}$ & $(22-322)$ \\
AFP & $>30,000 \mathrm{kU} / \mathrm{L}$ & $(0-10)$ \\
\hline I & &
\end{tabular}
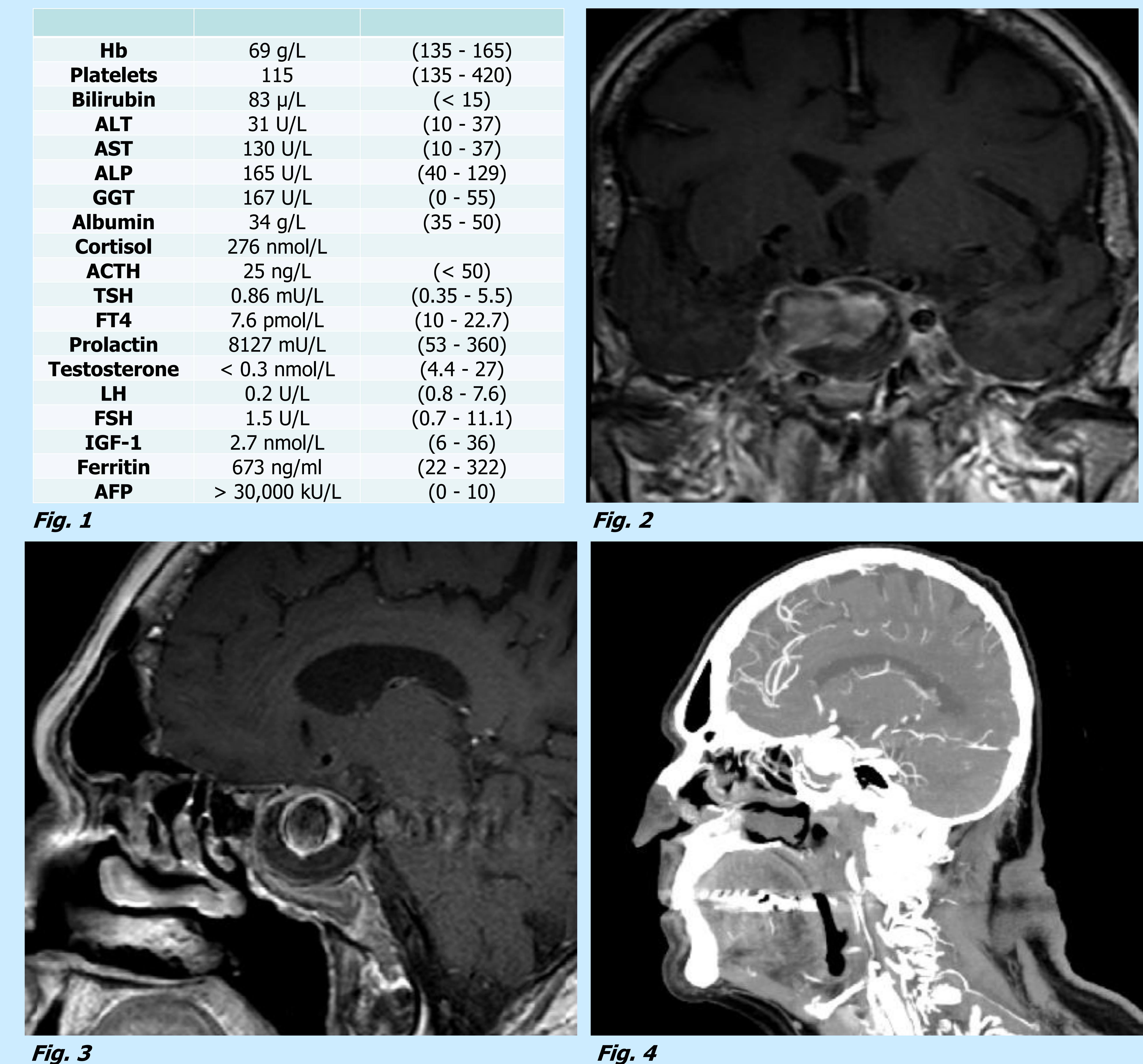

Fig. 2

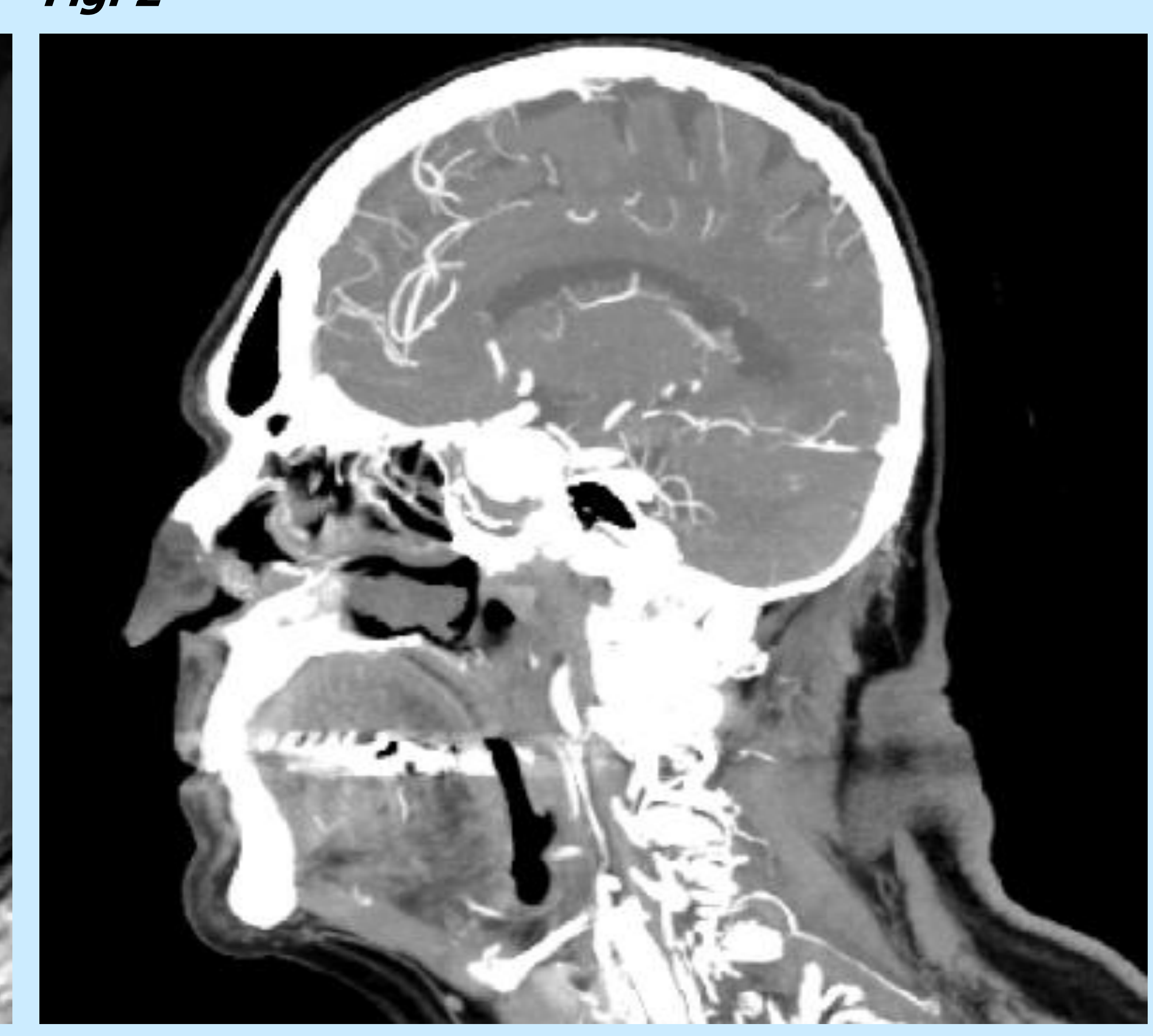

Fig. 4
- Discordant thyroid function tests prompted an anterior pituitary profile (Fig. 1).

- A gastroscopy, following an episode of melaena, demonstrated oesophageal varices.

- A CT thorax/abdomen/pelvis showed a portal vein thrombus and a $25 \mathrm{~mm}$ ill-defined high density right liver lobe lesion suspicious of hepatocellular carcinoma (HCC). An MRI liver with contrast demonstrated cirrhosis and extensive portal vein thrombosis.

- An MRI pituitary scan showed a 26 x 29 mm partially thrombosed aneurysm of the right internal carotid artery (Fig. 2 and Fig. 3).

- Subsequent CT angiography confirmed a partially thrombosed giant aneurysm from the cavernous segment of the right internal carotid artery extending into and expanding the pituitary fossa (Fig. 4).

- Therapeutic dose low molecular weight heparin was commenced after variceal banding.

- Hydrocortisone replacement was followed by levothyroxine.

- Neurovascular MDT discussion suggested conservative management in view of the poor prognosis.

\section{DISCUSSION}

Giant carotid aneurysms are a rare cause of hypopituitarism with a prevalence of $0.17 \%$, usually causing irreversible hypopituitarism. ${ }^{1}$ Intracranial aneurysms may mimic pituitary adenomas in both appearance and behaviour and should be considered as a differential diagnosis of hypopituitarism and hyperprolactinaemia. ${ }^{2}$ Pre-operative diagnosis is vital for a successful outcome in those undergoing surgery, as erroneous diagnosis of an adenoma could potentially result in severe perioperative haemorrhage..$^{1,3}$ Definitive diagnosis is often reached with computed tomography angiography to demonstrate arterial enhancement and direct communication with the internal carotid artery ${ }^{3}$, as was seen in the case we present. This is a rare and interesting case of hypopituitarism secondary to a carotid artery aneurysm complicating a new presentation of hepatocellular carcinoma. There are approximately 40 cases of hypopituitarism due to cerebral aneurysm reported in the literature ${ }^{2}$ and one case described as a first presentation of a gastric carcinoma. ${ }^{4}$ However, to our knowledge, this is the first reported case of a giant carotid artery aneurysm associated with hepatocellular carcinoma or portal vein thrombosis.

\section{References:}

1 Heshmati HM, Fatourechi V, Dagam SA, Piepgras DG. Hypopituitarism caused by intrasellar aneurysms. Mayo Clinic Proceedings. 2001. 76 (8):789-793.2

2 Gungor A, Gokkaya N, Bilen A, Bilen H, Akbas EM, Karadeniz Y, Eren S. Pituitary insufficiency and hyperprolactinemia associated with giant intra- and suprasellar carotid artery aneurysm. Case Rep Med. 2015 Jul 12.

3 Lawson EA, Buchbinder BR, Daniels GH. Hypopituitarism associated with a giant aneurysm of the internal carotid artery. J Clin Endocrinol Metab. 2008 Dec;93(12)

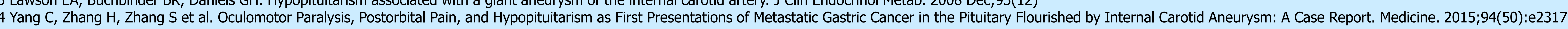

